\title{
CORRELATION OF ENDOSCOPIC AND HISTOLOGICAL FEATURES IN ADULTS WITH SUSPECTED CELIAC DISEASE IN A REFERRAL CENTER OF MINAS GERAIS, BRAZIL
}

\author{
Rodrigo Macedo ROSA ${ }^{1}$, Maria de Lourdes Abreu FERRARI ${ }^{2}$, Moisés Salgado PEDROSA ${ }^{3}$, \\ Gustavo Meirelles RIBEIRO ${ }^{4}$, Geraldo BRASILEIRO-FILHO ${ }^{3}$ and Aloísio Sales da CUNHA ${ }^{2}$
}

\begin{abstract}
Context - Clinical presentation of celiac disease is extremely variable and the diagnosis relies on serologic tests, mucosal intestinal biopsy and clinic and serologic response to a gluten-free diet. Objectives - To correlate the endoscopic and histological aspects of adult patients with suspicion of celiac disease and to evaluate the interobserver histological agreement. Method - Endoscopic aspects of 80 adult patients were evaluated and correlated with the histological features according the Marsh-Oberhuber classification system. The interobserver histological agreement was based on kappa values. Results - The symptoms of the patients varied largely, with prominence for chronic diarrhea, present in $48(60 \%)$ patients. The endoscopic aspects related with the duodenal villous atrophy had been observed in $32(40 \%)$ patients. There were confirmed 46 cases of celiac disease, with prevalence of $57.5 \%$. The sensitivity, specificity, positive predictive value and negative predictive value of the endoscopic markers for celiac disease diagnosis were of $60.9 \%, 88.2 \%, 87.5 \%$ and $62.5 \%$. There was moderate interobserver histological agreement (kappa $=0.46)$. Conclusions The endoscopic markers of villous atrophy, although not diagnostic, had assisted in the suspicion and indication of the duodenal biopsies for diagnosis proposal. Histology is sometimes contradictory and new biopsies or opinion of another professional can provide greater diagnostic agreement.
\end{abstract}

HEADINGS - Celiac disease, diagnosis. Endoscopy. Histology.

\section{INTRODUCTION}

Celiac disease $(\mathrm{CD})$ is a chronic gastrointestinal disorder in which ingestion of gluten, the protein fraction found in wheat, barley and rye, determines mucosal injury of the small intestine by autoimmune mechanisms in genetically predisposed individuals. Classically, is characterized by chronic mucosal inflammation that gradually leads to the development of intestinal villous atrophy. The removal of gluten from the diet provides clinical and histological improvement, while its reintroduction results in recurrence of the disease ${ }^{(14,29)}$.

The diagnosis of $\mathrm{CD}$ is based on clinical manifestations, laboratory tests, serological markers and histological aspects of the small intestine mucosa ${ }^{(1,10)}$. Nowadays, histological findings consistent with the disease are essentials for the diagnosis of the $\mathrm{CD}^{(3)}$.

The classic form of the disease manifested by chronic diarrhea and weight loss affects only a small portion of patients and most of them have atypical gastrointestinal manifestations, extraintestinal symptoms or even complete absence of symptoms. Despite the high prevalence $(0.7 \%-2 \%$ of the general population) $)^{(5,12,18,20,22,30,31)}$ and the availability of modern methods of investigation, the definitive diagnosis of CD remains challenging. For each new confirmed case of the disease, three to seven patients remain underdiagnosed ${ }^{(15,16,26,28)}$.

With the goal to contribute to the diagnosis of the disease, this study aimed to: (a) correlate the endoscopic aspects and histological findings accordind the Marsh-Oberhuber classification ${ }^{(23)}$ in an adult population with clinical and/or laboratory suspicion of CD; (b) evaluate the interobserver histological agreement among the three pathologists; and (c) describe the clinical and endoscopic characteristics of patients with confirmed diagnosis of CD.

Declared conflict of interest of all authors: non

Instituto Alfa de Gastroenterologia, Hospital das Clínicas, Universidade Federal de Minas Gerais - UFMG, Belo Horizonte, MG; ${ }^{2}$ Departamento de Medicina Interna da Faculdade de Medicina, UFMG. ${ }^{3}$ Departamento de Anatomia Patológica e Medicina Legal, UFMG; ${ }^{4}$ Escola de Medicina da Universidade Federal de Ouro Preto Ouro Preto. MG. Brasil.

Correspondence: Rodrigo Macedo Rosa. Rua Dr. Lucídio Avelar, 171/801, Bairro Buritis. CEP:30.455-790, Belo Horizonte, MG, Brasil. E-mail: rodrigogastro@yahoo.com.br 


\section{METHODS}

This study was conducted between March 2009 and December 2010 at the Digestive Endoscopy Unit of the Clinics Hospital of the Federal University of Minas Gerais, Belo Horizonte, Brazil. Adult patients with serological positive tests for CD or with symptoms of chronic diarrhea for more than 30 days, anemia by iron deficiency, weight loss of more than $5 \%$ of the body weight in 6 months and dermatitis herpetiformis were included in the study.

Besides the evaluation of clinical signs and symptoms of all patients, 51 of them underwent serological tests for $\mathrm{CD}$ by means of antigliadin (AGA), antiendomysium (EmA) and tissue transglutaminase (tTG) antibodies.

All patients underwent esophagogastroduodenoscopy (EGD) through endoscope with magnification (Fujinon EG-450 ZW) and single working channel of $2.8 \mathrm{~mm}$. In all patients, EGD was performed by the same researcher. A detailed study of the duodenum analyzing possible endoscopic changes with the aid of the water-immersion technique and magnification was conducted. The endoscopic findings potentially indicative of duodenal villous atrophy were: (a) reduction or absence of duodenal folds, (b) scalloping of folds, (c) visible submucosal vessels, (d) mosaic pattern, i.e., micronodular appearance of the mucosa, and (e) mucosal fissures, crevices, or grooves ${ }^{(4,8)}$. The final endoscopic diagnosis included three categories: (a) normal mucosa with preserved villous and no atrophy endoscopic markers; (b) partial villous atrophy with signs of mucosal atrophy and villous flattening; and (c) total mucosal atrophy with no villous present.

Biopsies were obtained by forceps with the diameter of $7.3 \mathrm{~mm}$ (FB 55K1, Olympus). Four specimens of the distal duodenum (second and third duodenal portions) and one of the proximal duodenum (duodenal bulb) from each patient were obtained. The fragments were placed on filter paper with the cut surface down, and the free surface up. The correct orientation of the fragments was confirmed with the aid of a magnifying glass. The specimens were fixed in $10 \%$ formalin solution.

The samples were routinely processed for paraffin embedding. Histological sections $5 \mu \mathrm{m}$ thick were stained with hematoxylin and eosin (HE). All slides were examined by three pathologists with good experience in the analysis of intestinal biopsies. In all cases, biopsies were considered adequate for analysis because they contained the entire thickness of the mucosa, including the muscularis mucosa and at least four continuous villi. Each pathologist issued his diagnosis according the Marsh-Oberhuber ${ }^{(23)}$ classification based on a 6-stage grading, namely: (1) type 1 infiltrative lesions, characterized by normal mucosal architecture with an increased number of intraepithelial lymphocytes (IEL), namely 40 or more lymphocytes per 100 enterocytes; (2) type 2 hyperplastic lesions, characterized by an increase in crypt depth without villous flattening and an increased number of IEL; (3) type 3a, 3b, and 3c destructive lesion, characterized by mild, marked, and complete villous flattening, respectively and an increased number of IEL; and (4) type 4 hypoplastic lesions, characterized by villous atrophy and normal crypt height and IEL count.

Statistical analysis was performed using R software, version 2.7.1, and Epi Info version 6.04. Initially, a descriptive analysis was made of the evaluated variables determining the frequencies and percentages for each objective variable and central tendency measures for the quantitative variables.

The agreement rates among the pathologists were evaluated based on multiple kappa coefficient. To assess the level of agreement among the three pathologists, kappa measure was determined, based on the number of agreeing responses. From the sample values, multiple kappa was estimated, as well as its respective $95 \%$ confidence interval (CI), and calculated the $P$-value. Since there was disagreement on the $\mathrm{CD}$ diagnosis among the three pathologies in the initial evaluation, the three pathologists jointly examined each case to reach a consensus diagnosis.

For endoscopic findings and their relation to the histological diagnosis of $\mathrm{CD}$, sensitivity, specificity, positive predictive value and negative predictive value were calculated. The likelihood ratio for a positive test and a negative test was also determined.

This study was approved by the Research Ethics Committee of the Federal University of Minas Gerais (ETIC 193/09). All patients provided written, informed consent prior to initiation of the study.

\section{RESULTS}

Eighty patients were included (mean age 38.4 years; 57 women). The endoscopic study of the duodenum with the water-immersion technique and magnification showed: (a) normal mucosa in 48 cases $(60 \%)$; (b) partial villous atrophy in $17(21.2 \%)$, and (c) total villous atrophy in $15(18.7 \%)$. The endoscopic signs of the 32 patients with signs of villous atrophy were: (a) visible submucosal vessels in $24(75 \%)$; (b) reduction or absence of mucosal folds in $24(75 \%)$; (c) scalloping of folds in $18(56.25 \%)$; (d) mucosal nodularity (mosaic pattern) in $13(40.62 \%)$; and (e) mucosal fissures, crevices or grooves in $12(37.5 \%)$ (Table 1) (Figure 1).

TABLE 1. Endoscopic aspects suggestive of duodenal villous atrophy $(\mathrm{n}=32)$

\begin{tabular}{lll}
\hline Endoscopic aspect & $\mathbf{n}$ & $\%$ \\
\hline Visible submucosal vessels & 24 & 75.00 \\
Reduction or absence of mucosal folds & 24 & 75.00 \\
Scalloping of folds & 18 & 56.25 \\
Mucosal nodularity (mosaic pattern) & 13 & 40.62 \\
Mucosal fissures, crevices or grooves & 12 & 37.50 \\
\hline
\end{tabular}



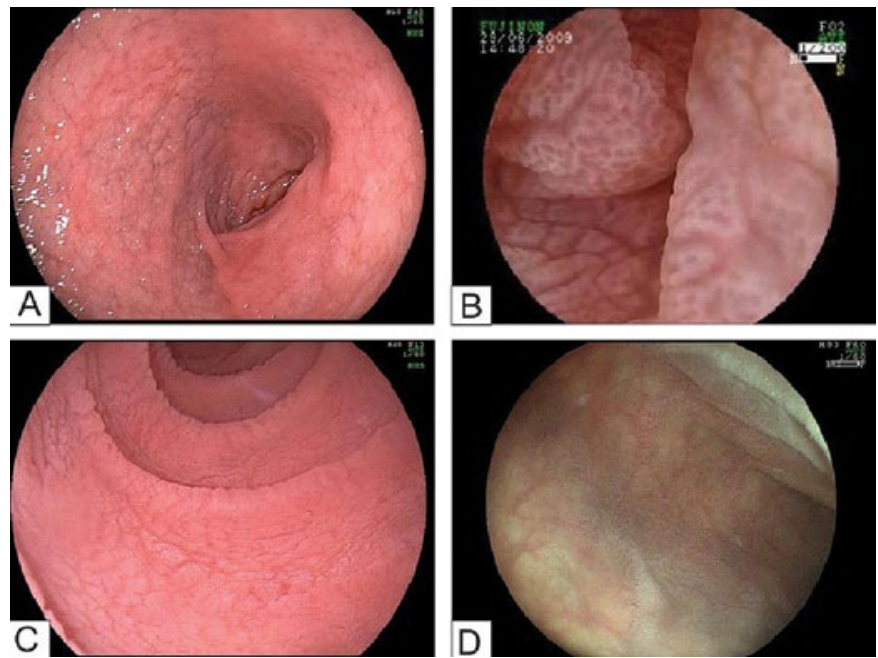

FIGURE 1. A: Duodenal bulb, mucosal nodularity/mosaic pattern; B: Total villous atrophy; water- immersion technique with magnification; $C$ : Second portion of the duodenum; water-immersion technique, mucosal fissures and scalloping of folds; D: Areas of total villous atrophy interspersed with areas of partial villous atrophy (patchy villous atrophy).

The results of the initial assessment by the three pathologists are shown in Table 2 and Figure 2. Kappa values was calculated among pathologists, two by two: (a) 0.62 between pathologists 1 and 2; (b) 0.27 between pathologists 1 and 3; and (c) 0.51 between pathologists 2 and 3. Global Kappa coefficient was 0.46 , indicating moderate agreement among the three pathologists $(95 \%$ CI between 0.39 and 0.53$)$.

When considering partial kappa values according to each
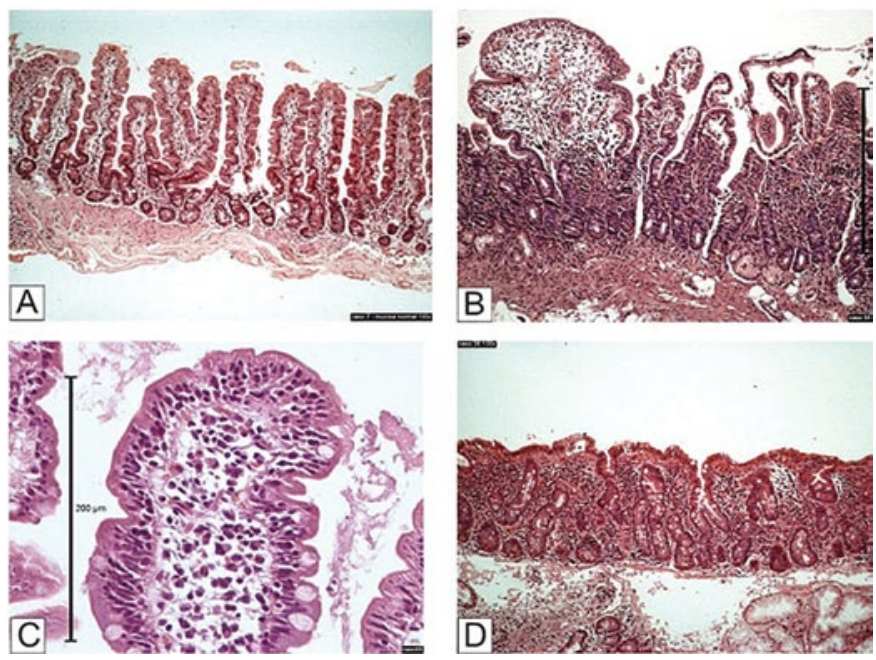

FIGURE 2. A: Normal mucosa with villus:crypt ratio preserved and no intraepithelial lymphocytosis. HE, 100X; B: Reduction of villus:crypt rate, partial villous atrophy, crypt hyperplasia and increased number of IEL. Destructive pattern, partial atrophy. HE, 100X; C: Detail of the previous case showing inflammatory infiltration and increased number of IEL. HE, 400X; D: Inversion of villus:crypt rate, total villous atrophy, crypt hyperplasia and increased number of IEL. Destructive pattern, total atrophy (flat mucosa). HE, 100X.

type of lesion, a fair agreement was found for the type $3 b$ $($ Kappa $=0.314)$, a moderate agreement for type 1 (Kap$\mathrm{pa}=0.495)$, and a good agreement for normal specimens and type $3 \mathrm{c}$ (Kappa $=0.603$ and 0.683 , respectively). For the type 3a, there was no statistical significance $(P$-value $=0.337)$. There was no histological diagnosis of type 2 and 4 (Table 3 ).

TABLE 2. Histological classification according Marsh-Oberhuber classification $(\mathrm{n}=80)$

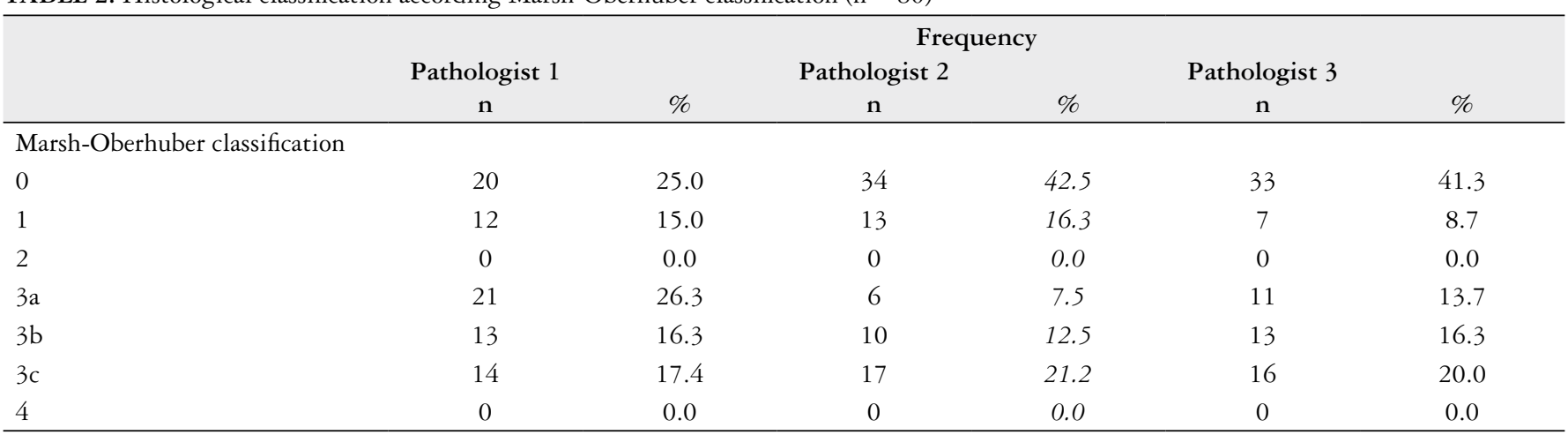

TABLE 3. Agreement among the three pathologists (Marsh-Oberhuber classification)

\begin{tabular}{lccc}
\hline Type & Kappa & CI*95\% & Value-P \\
\hline Normal & 0.603 & 0.48 to 0.73 & $<0.001$ \\
1 & 0.495 & 0.37 to 0.62 & --0.001 \\
2 & --- & --- & 0.337 \\
$3 \mathrm{a}$ & 0.062 & 0.00 to 0.19 & $<0.001$ \\
$3 \mathrm{~b}$ & 0.314 & 0.19 to 0.44 & $<0.001$ \\
$3 \mathrm{c}$ & 0.683 & 0.56 to 0.81 & -- \\
4 & --- & --- & \\
$*$ CI: confidence interval & & &
\end{tabular}


After the second histological evaluation performed simultaneously by the three pathologists, 46 cases $(57.5 \%)$ of CD were confirmed (mean age 37.4 years; 34 women). Patients characteristics and clinical data are described in Table 4. The endoscopic aspects were: (a) visible submucosal vessels in $23(50 \%)$; (b) reduction or absence of mucosal folds in 22 $(47.83 \%)$; (c) scalloping of folds in $18(39.13 \%)$; (d) mucosal nodularity (mosaic pattern) in $13(28.26 \%)$; and (e) mucosal fissures, crevices or grooves in $12(26.09 \%)$.

TABLE 4. Clinical data in patients with histological diagnosis of celiac disease $(n=46)$

\begin{tabular}{lcc}
\hline Signs/symptoms & n & $\%$ \\
\hline Chronic diarrhea (>30 days) & 27 & 58.69 \\
Dyspeptic complaints & 25 & 54.34 \\
Iron-deficiency anaemia & 16 & 34.78 \\
Family history of celiac disease (first degree relatives) & 7 & 15.21 \\
Weight loss (>5\% of body weight) & 6 & 13.04 \\
Dermatitis herpetiformis & 5 & 10.86 \\
Autoimmune diseases (two patients with two & 9 & 19.56 \\
associated diseases) & 7 & \\
$\quad$ Thyroid diseases (hypothyroidism/thyroiditis) & 2 & \\
$\quad$ Autoimmune atrophic gastritis of type A & 1 & \\
$\quad$ Autoimmune glomerulopathy & 1 & \\
$\quad$ Vitiligo & \multicolumn{1}{c}{} \\
\hline
\end{tabular}

Five patients with $\mathrm{CD}$ tested negative for serology: (a) two patients AGA IgA and $\operatorname{IgG}$ and $\mathrm{EmA} \operatorname{IgA}$, (b) one patient EmA IgA and tTG IgA, (c) two patients AGA IgA and IgG. The other tests were not performed in these patients. On the other hand, six patients without histological diagnosis of $\mathrm{CD}$ had at least one positive serologic test at the time of initial evaluation: (a) four patients AGA IgG, (b) one patient AGA $\operatorname{IgA},(\mathrm{c})$ one patient AGA IgA and IgG.

The correlation between endoscopic and histological findings showed: (a) among 48 normal endoscopic results, 30 had normal histology, 10 had the infiltrative type (no signs of villous atrophy) and 8 had partial villous atrophy not identified by the endoscopic examination; (b) from the 17 exams which partial villous atrophy at EGD, four had normal histology, two showed infiltrative type lesion with no villous atrophy, five cases were classified as partial villous atrophy and six as total atrophy; and (c) in 15 patients with endoscopic aspect of total villous atrophy, histology showed partial villous atrophy in four and total atrophy in 11 (Table 5).

TABLE 5. Final correlation between endoscopic and histological findings $(\mathrm{n}=80)$

\begin{tabular}{lccccc}
\hline \multicolumn{5}{c}{ HISTOLOGY } \\
Endoscopy & Normal & $\begin{array}{c}\text { Infiltrative } \\
\text { pattern }\end{array}$ & $\begin{array}{c}\text { Partial } \\
\text { atrophy }\end{array}$ & $\begin{array}{c}\text { Total } \\
\text { atrophy }\end{array}$ & Total \\
\hline Normal & 30 & 10 & 08 & --- & 48 \\
Partial atrophy & 04 & 02 & 05 & 06 & 17 \\
Total atrophy & ---- & --- & 04 & 11 & 15 \\
Total & 34 & 12 & 17 & 17 & 80 \\
\hline
\end{tabular}

For the whole group of patients, sensitivity, specificity, positive predictive value and negative predictive value of endoscopic findings as to the histological diagnosis of celiac disease was, respectively, $60.9 \%, 88.2 \%, 87.5 \%$ and $62.5 \%$. The positive likelihood ratio was 5.15 and negative likelihood ratio was 0.44 .

\section{DISCUSSION}

$\mathrm{CD}$ is a autoimmune disease with significant prevalence in the general population that can manifest at any age and shows a rather varied clinical presentation. Due to the large number of patients with nonspecific gastrointestinal and extraintestinal symptoms or even asymptomatic, diagnosis is often challenging ${ }^{(31)}$. Currently, an increase in the prevalence of the disease in its atypical manifestations is well known and less than one third of adult patients present chronic diarrhea ${ }^{(7)}$

In this study, the most prevalent clinical data in patients with histological diagnosis of $\mathrm{CD}$ were chronic diarrhea $(58.7 \%)$, dyspeptic manifestations $(54.3 \%)$ and iron-deficiency anemia (34.8\%). In this same group, five patients had negative serological tests for $\mathrm{CD}$ which can be explained by: (a) low sensitivity of AGA as a serological marker for CD, especially in adults; (b) observer-dependent limitation of the indirect immunofluorescence test for the detection of EmA IgA antibodies, negative in three cases, and (c) lack of routine tests for primary deficiency of IgA, a notably important fact, especially in the isolated case of negative tTG IgA. This deficiency is associated with several autoimmune diseases including DC and is the most common of all primary immunodeficiency, varying its prevalence according to ethnic profile of each population ${ }^{(19)}$. In this study, primary IgA deficiency was confirmed in one patient. On the other hand, six patients had positive serology without histological confirmation of CD. In such cases, serological testing was positive for AGA IgA and IgG. It is well known that this serologic marker has poor sensitivity and specificity for CD diagnosis in adults and false-positive results are possible. In three of these patients, EmA and tTG IgA were negative. There were no cases of EmA or tTG IgA positive in patients with normal histology, i.e. positivity for these antibodies have high predictive value for CD.

Due to the wide variability of the clinical manifestations and laboratory abnormalities associated with $\mathrm{CD}$, the active search for diagnosis is crucial, as proposed by Green and Cellier ${ }^{(13)}$. These authors have suggested endoscopic duodenal biopsies in all patients with positive serology for $\mathrm{CD}$ and/ or those with chronic diarrhea, iron-deficiency anemia or weight-loss, irrespectively of serologic tests. Recent guidelines from the National Institute of Clinical Excellence in the United Kingdom recommended offering or considering serum testing for $\mathrm{CD}$ in a wide and variable spectrum of clinical settings ${ }^{(21)}$

Many studies point out the importance of the endoscopic aspect of the duodenal mucosa in $\mathrm{CD}$ diagnosis, highlighting as main changes: (a) reduction or absence of duodenal folds; 
(b) scalloping of folds; (c) visible submucosal vessels; (d) mosaic pattern, i.e. micronodular or cobblestone appearance of the mucosal surface, and (e) mucosal fissures, crevices, or grooves ${ }^{(4,8)}$. In a recent review, the sensitivity and specificity of endoscopic markers for the diagnosis of $\mathrm{CD}$ varied, respectively, between $6 \%$ and $94 \%$ and $83 \%$ and $100 \%{ }^{(4)}$.

In the present study, no case with normal endoscopic appearance of the duodenal mucosa had histological diagnosis of total villous atrophy. Similarly, no case initially classified by endoscopy as compatible with total villous atrophy had normal histology, demonstrating partial villous atrophy in four cases and total atrophy in 11. There was a certain amount of limitation concerning 17 patients endoscopically classified as partial villous atrophy. Villous were histological preserved in six cases (four normal and two with infiltrative pattern) and, among the remaining 11, five showed partial villous atrophy and six were compatible with total atrophy.

All endoscopic findings related to villous atrophy were observed in this study, with emphasis on visible submucosal vessels and reduction or absence of mucosal folds. Rates of sensitivity, specificity, positive predictive value and negative predictive value of endoscopic markers for the diagnosis of CD were, respectively, $60.9 \%, 88.2 \%, 87.5 \%$ and $62.5 \%$. The sensitivity, only moderate, showed that a significant number of affected individuals showed no mucosal alterations evidenced by endoscopic examination. The high specificity of the test indicates that individuals without $C D$ show no endoscopic abnormalities. The positive (5.16) and negative likelihood ratios (0.44) indicate low diagnostic value of isolated EGD for CD diagnosis. Among patients with $\mathrm{CD}$, all endoscopic findings of villous atrophy were also observed, with greater emphasis on visible submucosal vessels and reduction or absence of mucosal folds, found in $23(50 \%)$ and $22(47.8 \%)$ cases, respectively. On the other hand, the absence of endoscopic markers in some patients with CD may be due to: (a) disease without villous atrophy, i.e., infiltrative and hyperplastic types (Marsh-Oberhuber types 1 and 2); (b) disease with partial villous atrophy, difficult to characterize by endoscopic examination, and (c) patients with patchy villous atrophy, presenting interspersed atrophy areas with preserved villous areas.

Oxentenko et al. ${ }^{(25)}$ suggested that endoscopic markers alone, due to their low sensitivity, would not be useful in identifying patients with subclinical or atypical CD and recommended duodenal biopsies in patients with clinical suspicion of the disease, regardless of the existence of endoscopic changes. From a practical standpoint, the recognition of any endoscopic change in the mucosa related to villous atrophy sets an absolute indication for duodenal biopsy. The absence of endoscopic markers does not exclude the diagnosis and biopsies should be made in cases of clinical and/or laboratory suspicion of $\mathrm{CD}^{(4,8)}$.

In cases of total villous atrophy, EGD has high diagnostic accuracy. Cammarota et al..$^{(2,4)}$ proposed new endoscopic strategy according to which the endoscopic view of complete duodenal villous atrophy is sufficiently specific to avoid the need for biopsy in patients at high-risk of $\mathrm{CD}$, which could save time and reduce costs. Despite the fact that is an interesting proposal, such conduct is not yet validated. Furthermore, villous atrophy may be present in other intestinal diseases in addition to CD and endoscopic markers of atrophy are not sufficient for a final diagnosis to which a biopsy remains mandatory $(6,8,17)$.

Some considerations are important about the histological study. First, biopsies must be multiple, preferably between four to six, and at least one from the duodenal bulb by the possibility of irregular involvement of the mucosa, sometimes with histological changes restricted to this region. In clinical practice, biopsies taken in conjunction with the second and/or third portions of the duodenum would have the potential to confirm the histological diagnosis in all cases of $\mathrm{CD}^{(3,27)}$. Technical care is essential in obtaining adequate samples for histological evaluation. The use of good quality endoscopic forceps, to avoid mechanical trauma to the specimens and the careful transfer of fragments to the filter paper for correct guidance, with its free surface upwards and the cutting surface downwards, certainly contribute to a more accurate histological interpretation ${ }^{(11)}$.

Marsh's classification, modified by Oberhuber et al. ${ }^{(23)}$, is the histological classification system of CD most widespread and used worldwide, both for diagnostic purposes and for histological reevaluation after institution of gluten-free $\operatorname{diet}^{(23,24)}$. It provides fast and precise classification of intestinal lesions both at the moment of initial diagnosis and in the follow-up. The severity of the lesions found in different biopsies, obtained at different times, can be readily compared, a fact that is especially useful in patients with slow response to the gluten-free diet. Moreover, since it is adopted all over the world, such classification allows the comparison of data obtained by different research groups.

There was great diagnostic variability among the three pathologists participating in the study. Kappa values obtained separately for each pair of pathologists were $0.62,0.51$ and 0.27 , with a mean kappa of 0.46 , indicating moderate agreement. The highest rates of interobserver agreement were found in polar histological conditions, such as normal mucosa and total villous atrophy (type 3c), with Kappa values of 0.603 and 0.683 (good agreement), respectively. The intermediate situations, without villous atrophy (type 1) or with severe villous atrophy (type $3 \mathrm{~b}$ ) showed concordance rates slightly below ( 0.495 and 0.314$)$, respectively. In cases with mild/moderate villous atrophy (type $3 \mathrm{a}$ ), there was no agreement $(0.062, P=0.337)$.

Despite the importance of intestinal biopsy as an essential component in the diagnosis of $\mathrm{CD}$, its interpretation must always be associated with clinical, serological and endoscopic data. Dickson et al. ${ }^{(9)}$ drew attention to the histological report describing the relevant findings. When indicated, the pathologist may recommend serologic tests and new follow-up biopsies or request the opinions of other experienced professional in gastrointestinal pathology. These recommendations would have the objective of providing better standardization and enable greater agreement among pathologists, clinicians and endoscopists. 
In summary, in this study the clinical profile of $\mathrm{CD}$ varied largely, confirming the findings of many studies that the disease presents itself increasingly in its atypical form. The EGD proved to be more effective when there were clear signs of villous atrophy but in cases with less intense changes, such as in infiltrative lesions, endoscopic findings were not sufficient for diagnosis. The positive and negative likelihood ratios indicated low diagnostic power of EGD as an isolated exam. Obtaining five fragments from the duodenal mucosa (one from the bulb and four from the second and third portions of the duodenum) and their correct orientation on filter paper were valuable in the preparation of histological sections and evaluation. The agreement among pathologists was only moderate, being more robust at the far end of the spectrum (normal mucosa and total villous atrophy).

\section{ACKNOWLEDGMENTS}

Prof. Eduardo Garcia Vilela (Department of Internal Medicine of the School of Medicine of the Federal University of Minas Gerais, Belo Horizonte, Brazil).

Rosa RM, Ferrari MLA, Pedrosa MS, Ribeiro GM, Brasileiro-Filho G, Cunha AS. Correlação entre os aspectos endoscópicos e histológicos de pacientes adultos com suspeita de doença celíaca em um centro de referência de Minas Gerais, Brasil. Arq Gastroenterol. 2014,51(4):290-6.

RESUMO - Contexto - A apresentação clínica da doença celíaca é extremamente variável e o diagnóstico se baseia em testes sorológicos, histologia intestinal e respostas clínica e sorológica à dieta sem glúten. Objetivos - Correlacionar os aspectos endoscópicos e histológicos de pacientes adultos com suspeita de doença celíaca e avaliar a concordância histológica interobservadores. Método - Os aspectos endoscópicos de 80 pacientes adultos foram avaliados e correlacionados com os achados histológicos de acordo com a classificação de Marsh-Oberhuber. A concordância histológica foi baseada nos valores kappa. Resultados - A sintomatologia clínica foi muito variável com destaque para a diarréia crônica, presente em 48 (60\%) pacientes. Os aspectos endoscópicos relacionados à atrofia vilositária duodenal foram observados em $32(40 \%)$ pacientes. Foram confirmados 46 casos de doença celíaca, prevalência de $57.5 \%$. A sensibilidade, a especificidade, o valor preditivo positivo e o valor preditivo negativo dos aspectos endoscópicos para o diagnóstico da doença celíaca foram, respectivamente, $60,9 \%, 88,2 \%, 87,5 \%$ e $62,5 \%$. A concordância histológica interobservadores foi moderada (kappa = 0,46). Conclusões - Os aspectos endoscópicos de atrofia vilositária contribuíram para a suspeita e a indicação das biópsias duodenais com objetivo diagnóstico. A histologia pode ser contraditória e novas biópsias ou a opinião de outro profissional podem propiciar maior concordância diagnóstica.

DESCRITORES - Doença celíaca, diagnóstico. Endoscopia. Histologia. 


\section{REFERENCES}

1. Abdulkarim AS, Murray JA. Review article: The diagnosis of coeliac disease Aliment Pharmacol Ther. 2003;17:987-95.

2. Cammarota G, Cesaro P, Martino A, Zuccalà G, Cianci R, Nista E, et al. High accuracy and cost-effectiveness of a biopsy-avoiding endoscopic approach in diagnosing coeliac disease. Aliment Pharmacol Ther. 2006;23:61-9.

3. Cammarota G, Cesaro P, La Mura R, Martino A, Cazzato A, Miele L, et al. Role of the "immersion technique" in diagnosing celiac disease with villous atrophy limited to the duodenal bulb. J Clin Gastroenterol. 2007;41:571-75.

4. Cammarota G, Fedeli P, Gasbarrini A. Emerging technologies in upper gastrointestinal endoscopy and celiac disease. Nat Clin Pract Gastroenterol Hepatol. 2009;6:47-56.

5. Catassi C, Kryszak D, Louis-Jacques O, Duerksen DR, Hill I, Crowe SE, et al Detection of Celiac disease in primary care: a multicenter case-finding study in North America. Am J Gastroenterol. 2007;102:1454-60.

6. Di Sabatino A, Corazza GR. Coeliac disease. Lancet. 2009;373:1480-93.

7. Dickey W, McMillan SA. Increasing numbers at a specialist coeliac clinic: contribution of serological testing in primary care. Dig Liver Dis. 2005;37:928-33.

8. Dickey W. Endoscopic markers for celiac disease. Nat Clin Pract Gastroentero Hepatol. 2006;3:546-51.

9. Dickson BC, Streutker CJ, Chetty R. Coeliac disease: an update for pathologists J Clin Pathol. 2006;59:1008-16.

10. Fasano A, Araya M, Bhatnagar S, Cameron D, Catassi C, Dirks M, et al. Federation of International Societies of Pediatric Gastroenterology, Hepatology, and Nutrition consensus report on celiac disease. J Pediatr Gastroenterol Nutr. 2008;47:214-19.

11. Freeman HJ. Pearls and pitfalls in the diagnosis of adult celiac disease. Can $\mathbf{J}$ Gastroenterol. 2008;22:273-80.

12. Gandolfi L, Pratesi R, Cordoba JC, Tauil PL, Gasparin M, Catassi C. Prevalence of celiac disease among blood donors in Brazil. Am J Gastroenterol. 2000;95: 689-92.

13. Green PH, Cellier C. Celiac disease. N Engl J Med. 2007;357:1731-43.

14. Green PH, Jabri B. Coeliac disease. Lancet. 2003;362:383-91.

15. Green PH. Where are all those patients with Celiac disease? Am J Gastroenterol. 2007;102:1461-63.

16. Green PHR, Stavropoulos SN, Panagi SG, Goldstein SL, Mcmahon DJ, Absan $\mathrm{H}$, Neugut AI. Characteristics of adult celiac disease in the USA: results of a national survey. Am J Gastroenterol. 2001;96:126-31.
17. Lee SK, Green PHR. Endoscopy in celiac disease. Curr Opin Gastreonterol. 2005;21:589-94.

18. Lo W, Sano K, Lebwohl B, Diamond B, Green PH. Changing presentation of adult celiac disease. Dig Dis Sci. 2003;48:395-98.

19. Mantovani AP, Monclaro MP, Skare TL. Prevalence of IgA deficiency in adult systemic lupus erythematosus and the study of the association with its clinical and autoantibody profiles. Rev Bras Reumatol. 2010;50:273-82.

20. Murray JA, Van Dyke C, Plevak MF, Dierkhising RA, Zinsmeister AR, Melton LJ 3 rd. Trends in the identification and clinical features of celiac disease in a North American community, 1950-2001. Clin Gastroenterol Hepatol. 2003;1:19-27.

21. National Institute for Clinical Excellence (NICE) guidelines - Coeliac disease Recognition and assessment of coeliac disease. [Internet]. [Cited 2014 Mar 10]. Available from: http://www.nice.org.uk/nicemedia/pdf/ CG87FullGuideline.pdf.

22. National Institutes of Health Consensus Development Conference Statement on Celiac Disease, June 28-30, 2004. Gastroenterology. 2005;128(4 Suppl 1):S1-9.

23. Oberhuber G, Granditsch G, Vogelsang H. The histopathology of coeliac disease: time for a standardized report scheme for pathologists. Eur J Gastroenterol Hepatol. 1999;11:1185-94.

24. Oberhuber G. Histopathology of celiac disease. Biomed Pharmacother 2000;54:368-72.

25. Oxentenko AS, Grisolano SW, Murray JA, Burgart LJ, Dierkhising RA, Alexander JA. The insensitivity of endoscopic markers in celiac disease. Am J Gastroenterol. 2002;97:933-8

26. Rampertab SD, Pooran N, Brar P, Singh P, Green PH. Trends in the presentation of celiac disease. Am J Med. 2006;119:355.e9-14.

27. Rashid M, MacDonald A. Importance of duodenal bulb biopsies in children for diagnosis of celiac disease in clinical practice. BMC Gastroenterol. 2009;9:78

28. Rewers M. Epidemiology of celiac disease: what are the prevalence, incidence, and progression of celiac disease? Gastroenterology. 2005;128(4 Suppl 1):S47-51.

29. Rostom A, Murray JA, Kagnoff MF. American Gastroenterological Association (AGA) institute technical review on the diagnosis and management of celiac disease. Gastroenterology. 2006;131:1981-2002.

30. Rubio-Tapia A, Murray JA. Celiac disease beyond the gut. Clin Gastroenterol Hepatol. 2008;6:722-3.

31. Volta U, Villanacci V. Celiac disease: diagnostic criteria in progress. Cell Mol Immunol. 2011;8:96-102. 